\title{
Ankylosing Spondylitis in a 44-Year-0ld Nigerian Man: A Case Report
}

\author{
Michael Bundepuun Ode*, Icha Inalegwu Onche, David Ghorau Mancha, Idumagbodi Amupitan \\ Department of Orthopaedics and Trauma, Faculty of Clinical Sciences, College of Health Sciences, University of Jos, Jos, \\ Nigeria \\ Email: *odemb2014@gmail.com
}

How to cite this paper: Ode, M.B., Onche, I.I., Mancha, D.G. and Amupitan, I. (2021) Ankylosing Spondylitis in a 44-Year-Old Nigerian Man: A Case Report. Journal of Biosciences and Medicines, 9, 51-58. https://doi.org/10.4236/jbm.2021.98005

Received: July 13, 2021

Accepted: August 7, 2021

Published: August 10, 2021

Copyright (๑) 2021 by author(s) and Scientific Research Publishing Inc. This work is licensed under the Creative Commons Attribution International License (CC BY 4.0).

http://creativecommons.org/licenses/by/4.0/

\begin{abstract}
Ankylosing spondylitis (AS) is a rare inflammatory disorder that affects the axial skeleton. It is characterized by inflammation of the joints of the spine with subsequent bridging of the spinal segments resulting in a reduced mobility of the spine and subsequent stiffness of the spine. It can be a severely limiting condition adversely affecting the quality of life of affected individuals. It has been found to be commoner in Caucasians and Asians but rare in blacks in the Americas with few cases reported amongst the African Black population. It is associated with the occurrence of the major histocompatibility complex (MHC) class 1 allele HLA-B27. We present the case of a 44-yearold Nigerian man presenting with a 21-year history of progressively worsening back pain and stiffness associated with hip pain and difficulty in extending his neck. He had no extraspinal manifestations. He was diagnosed with Ankylosing Spondylitis using the modified New York criteria. He was commenced on selective COX2 inhibitors and a physical therapy program aimed at improving the flexibility of the spine and reducing pain. He had a significant improvement in his pain and improved flexibility of his spine in all planes. Ankylosing spondylitis affects the axial skeleton primarily but there may be some extra spinal manifestations such as anterior uveitis, psoriasis and inflammatory bowel disease. Various modalities are employed in its treatment ranging from physical therapy, drugs e.g. Nonsteroidal anti-inflammatory drugs, tumour necrosis factor inbibitors and surgery where complications arise. These have proven effective in improving the symptoms of the disease and quality of life.
\end{abstract}

\section{Keywords}

Ankylosing Spondylitis, Black, Nigerian, Man, 44 Years 


\section{Introduction}

Ankylosing spondylitis is a subtype of a group of rheumatic conditions affecting the spine known as spondyloarthritis. It is regarded as a chronic inflammatory disease affecting the spine with an autoimmune component. It is a condition that arises from a combination of genetic, immunological, microbial and endocrine factors [1]. It has been found to be commonest in the Northern Artic countries and rare in blacks of African descent [1] [2] [3] [4]. It affects men more commonly and typically the onset of the condition is within the second and third decades of life [5]. The condition is characterized by a chronic low back pain and pain around the hips. The pain is worse after periods of prolonged immobilization such as early in the mornings and improves with activity. There is a gradual loss of flexibility of the spine which can progress to a stiff spine limiting axial movements and may be complicated by a kyphosis of the spine. It significantly impairs quality of life [6]. AS is closely linked to the presence of the major histocompatibility complex class 1 allele HLA-B27 and it has been found to occur more commonly in populations with HLA-B27 positivity even though AS occurs in HLA-B27 negative individuals [7] [8]. The pathology of AS occurs where the ligaments, capsule and tendons attach to bone especially around the spine and the ribs. There is an inflammatory process mediated by tumour necrosis factor which results in an erosion of the bone and then attempts at healing by bony spur formation, which can bridge the spine segments resulting in a fusion of adjoining segments of the spine [9]. The diagnosis of AS is made by a combination of clinical, radiological and laboratory factors. Various diagnostic criteria and classification systems have been made by several bodies such as; the Modified New York criteria, Assessment of Spondylo Arthritis International Society (ASAS), the European Spondyloarthropathy Study Group (ESSG) criteria and the Amor criteria [10]. The clinical and radiological criteria in combination are considered the more significant factors. The spine in the affected patient can become so stiff and fixed that the neck of the patient may adopt a fixed position in flexion limiting the gaze of the patient to just a few footsteps ahead. The rib cage may be affected limiting the expansion of the rib cage during respiration. Extra osseous manifestations in AS include uveitis and aortitis and aortic valve abnormalities as well as psoriasis and inflammatory bowel disease. Treatment of AS is geared towards reducing pain and inflammation, maintaining a supple and flexible spine and correcting established deformities. Various modalities are employed which include; physical therapy, Non-Steroidal anti-inflammatory drugs (NSAIDs), disease modifying anti-rheumatic drugs such as methotrexate and tumour necrosis factor inhibitors (TNFi). Surgery is employed to correct deformities such as spinal osteotomies to realign the spine or total hip replacement to restore destroyed joints [5] [8] [11]. Physical therapy and NSAIDs particularly selective cyclooxygenase 2 inhibitors and TNFi have been regarded as the mainstay of treatment and have been preferred as continuous therapies as opposed to on-demand treatments [12] [13]. We present the case of a 44-year-old 
Nigerian man who was diagnosed with AS.

\section{Case Report}

DN is a 44-year-old man who presented with a history of back and hip pain which started 21 years ago. The pain was of insidious onset. There was no preceding history of trauma to the back and the onset was not associated with activity. The pain was associated with stiffness at the back. There was associated neck pain of similar duration and onset. In the two years preceding presentation, the pain occurred more frequently and lasted for longer periods before he had relief. He noticed that the pain and stiffness was worse at night and early in the mornings. His back became progressively stiffer with resultant difficulty in twisting his trunk. There was also a worsening ability to extend his neck. There was an associated pain, swelling and stiffness in the fingers of his right hand. None of his close relatives had similar symptoms. There was no radiculopathy noticed with the above symptoms. There were no eye abnormalities or skin changes. $\mathrm{He}$ had no change in his bowel habit. He weighed eighty kilograms and was one hundred and seventy five meters tall with a body mass index (BMI) of 26.1. He was a nonsmoker. The back pain and limitation of the trunk and neck movements had affected his work as an engineer and social life, especially recreational sports (Golfing). When examined, he had a limitation of the spine movements in three planes as well as an exacerbation of the pain when the spine was moved beyond these points both actively and passively. He had lumbo sacral and cervical $\mathrm{X}$ rays done which showed bridging of the spinal segments with bony spurs and a straightening of the lumbar spine (bamboo spine). There was also increased sclerosis at the vertebral body margins Figure 1 as well as sacroilitis Figure 2. In the cervical spine, there was a loss of cervical lordosis with the bridging of the spinal segments by bony spurs as well as sclerosis of the vertebral bodies posteriorly Figure 3 . He had an elevated erythrocyte sedimentation rate of $59 \mathrm{~mm}$ in the first hour. A diagnosis of Ankylosisng spondylitis was made taking into cognizance the clinical and radiological features noted in him, using the modified New York criteria as well as the Amor criteria for the diagnosis of AS. He had a score of 8 using the Amor criteria. He was commenced on physical therapy to improve the mobility and flexibility of the spine as well as Non-Steroidal Anti Inflammatory Drugs (NSAIDS). Celecoxib a selective cyclo oxygenase 2 (COX2) inhibitor was used. A physical therapy program was commenced which included infrared therapy, $\mathrm{Z}$ thrusts, transverse manipulations, spinal mobility exercises and phonophoresis using diclofenac gels. He also had a home schedule of physical therapy which included active trunk and neck exercises to be done morning and evening. He was maintained on a continuous regimen of celecoxib with periodic monitoring of renal and hepatic parameters. On follow up visits, he had a reduction in the frequency and duration of the back pain with a pain severity reduction on the numeric pain scale from 9 to 4 . He had increased range of motion in all planes in the trunk and he had resumed 


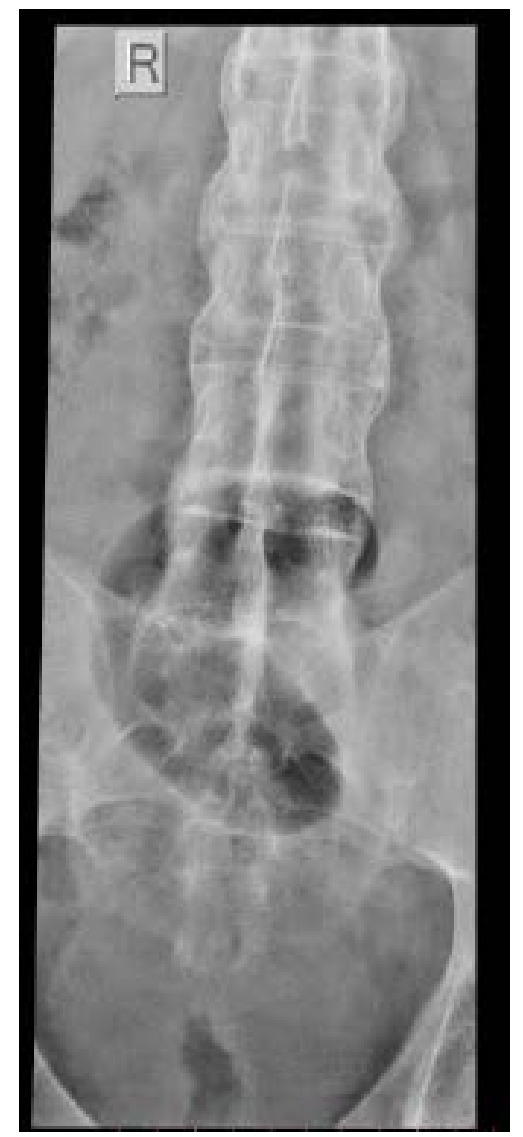

Figure 1. Antero posterior view of Lumbo sacral X ray.

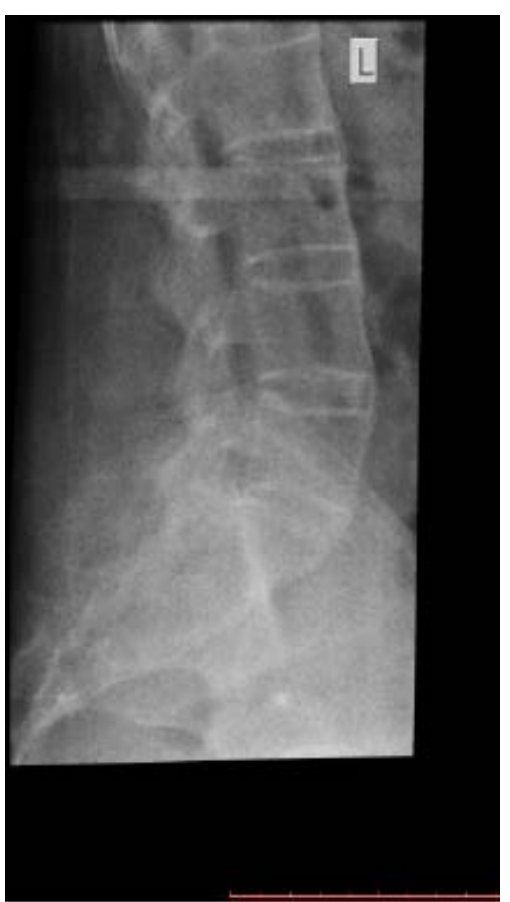

Figure 2. Lateral view of Lumbo sacral X ray. 


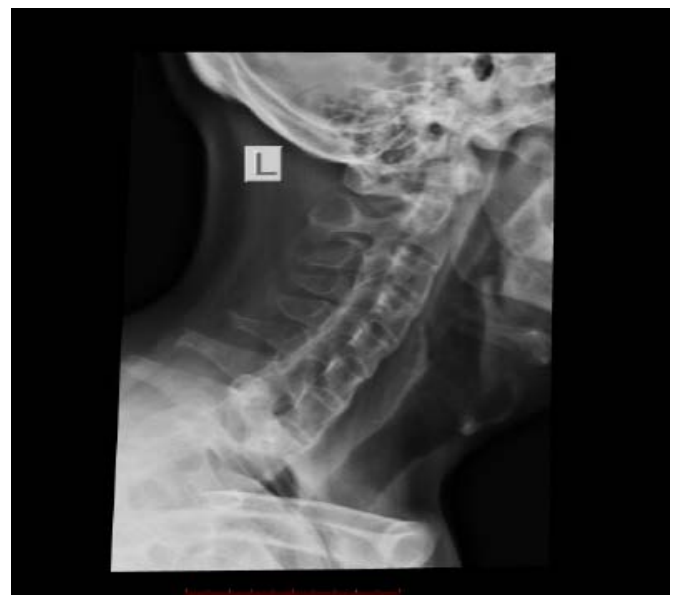

Figure 3. X ray of the cervical spine.

playing golf with greater ease. He was counseled on his condition and about the chronic nature of the condition with the possible complications that may occur and the need for a long term follow up.

\section{Discussion}

Ankylosing spondylitis is a chronic inflammatory autoimmune mediated condition that typically affects the spine and sacroiliac joints with extra-axial manifestations in the forms of uveitis, aortitis, valvular disorders and psoriasis. There may also be manifestations in the fingers [14]. It forms a subtype of spondyloarthritis. The prevalence of AS has been found mostly in the North Arctic populations and in other caucasiains and Asians with very few cases reported in Blacks [15]. A South Africa study on spondyloarthritis over a five-year period in the rheumatology clinic showed a complete absence of Ankylosing spondylitis in blacks [3]. A systematic review by Stolwijk C and colleague showed that this was a rare condition in blacks [1]. The condition usually arises in the second and third decades of life and this was the scenario in the case presented who first noticed symptoms of the condition at the age of 23. It is a chronic condition with intermittent spells and periods of relief. There is however a continuous worsening of the back pain and the loss of spinal flexibility. The patient presented here started having back and hip pain which subsequently involved the neck. The radiographs showed the typical bamboo spine, where there was a bridging of the spinal segments by the bony spurs which had been formed due to the continuous inflammation, erosion of bone and attempts at healing with spur deposition that bridged the spinal segments. The diagnosis of AS is usually made by employing a combination of clinical parameters, imaging and laboratory parameters to satisfy certain criteria. The above patient met the criteria for diagnosis using the modified New York criteria. He had limitation of spinal movements in all planes, chronic back pain in the spine as well as sacroilitis. He scored a total of 8 using the Amor criteria which is diagnostic when an individual scores 6 pointsor more. There are otherdiagnostic criteria by various bodies which take into con- 
sideration factors such as Magnetic resonance imaging findings, HLA B27 positivity and elevations in the ESR and C. Reactive protein levels. ESR and C reactive protein levels are believed to be elevated mainly when there is an acute exacerbation of the disease process. The patient had no extra skeletal manisfestation such as anterior uveitis. This sort of presentation with no extra skeletal manifestation is seen in HLA-B27 negative individuals and in causasians negative for HLA-B27. The disease process in such affected individuals has been shown to run a milder course [15]. The treatment of AS has evolved over the years with various modalities employed. Physical therapy is employed to maintain a supple and flexible spine. It is preferred that such physical therapy is continuous. Basakci et al. in their randomized controlled study showed significant improvement in spinal flexibility and function when aerobic exercises and spinal mobility exercises where offered to patients diagnosed with AS [11]. The Use of NSAIDs is to limit the inflammatory process which is a main contributor to the pathogenesis of the disease. It has been shown that COX2 inhibitors have better outcomes compared to other NSAIDs and that a continuous administration regimen is preferred [12] [13]. The COX2 inhibitors have been shown to have a good safety profile with a lower risk of gastrointestinal events when compared to other NSAIDs [13]. Zhu W et al. in their publication showed that NSAIDs particularly COX2 Inhibitors are considered as first line drugs in the treatment of AS and this is in line with the guidelines of various expert panels [8]. Disease modifying anti-rheumatic drugs such as methothrexate has also been employed in the treatment of AS [16]. Tumour necrosis factor inhibitors such as infliximab, etanercept and adalimumab have been found to be very effective in the treatment of AS as they have been shown to result in significant relief of symptoms [17] [18] [19]. These drugs are however not readily available in our environment. Surgery is employed in AS when complications arise from the course of the disease. Total hip replacements for hip joint disease, vertebral Osteotomies to correct posture and surgery for vertebral body collapse [20].

\section{Conclusion}

Ankylosing spondylitis typically affects the axial skeleton and affects adversely the quality of life of affected individuals. Even though it occurs infrequently in blacks, it should be suspected in patients presenting with a history of chronic low back pain and an increasing limitation in spine movements. Treatment with physical therapy, NSAIDs and other drugs are effective.

\section{Consent}

Consent was obtained from the patient with the assurance that patient's identity would be protected.

\section{Conflicts of Interest}

The authors have no conflict of interest to declare. 


\section{References}

[1] Stolwijk, C., van Onna, M., Boonen, A. and van Tubergen, A. (2016) Global Prevalence of Spondyloarthritis: A Systematic Review and Meta-Regression Analysis. Arthritis care \& Research, 68, 1320-1331. https://doi.org/10.1002/acr.22831

[2] Usenbo, A., Kramer, V., Young, T. and Musekiwa, A. (2015) Prevalence of Arthritis in Africa: A Systematic Review and Meta-Analysis. PLoS ONE, 10, e0133858. https://doi.org/10.1371/journal.pone.0133858

[3] Maharaj, A.B. and Tak, P.P. (2015) Spondyloarthritis in African Blacks. The Journal of Rheumatology, 42, 139. https://doi.org/10.3899/jrheum.141023

[4] Dean, L.E., Jones, G.T., MacDonald, A.G., Downham, C., Sturrock, R.D. and Macfarlane, G.J. (2014) Global Prevalence of Ankylosing Spondylitis. Rheumatology, 53, 650-657. https://doi.org/10.1093/rheumatology/ket387

[5] Ben Abdelghani, K., Gzam, Y., Fazaa, A., Miladi, S., Sellami, M., Souabni, L., Kassab, S., Chekili, S., Zakraoui, L. and Laater, A. (2021) Non-Radiographic Axial Spondyloarthritis in Tunisia: Main Characteristics and Detailed Comparison with Ankylosing Spondylitis. Clinical Rheumatology, 40, 1361-1367. https://doi.org/10.1007/s10067-020-05415-7

[6] Hammoudeh, M., Abdulaziz, S., Alosaimi, H., Al-Rayes, H., Aldeen Sarakbi, H., Baamer, M., Baraliakos, X., Dahou Makhloufi, C., Janoudi, N., Shirazy, K., Sieper, J. and Sukhbir, U. (2016) Challenges of Diagnosis and Management of Axial Spondyloarthritis in North Africa and the Middle East: An Expert Consensus. The Journal of International Medical Research, 44, 216-230.

https://doi.org/10.1177/0300060515611536

[7] Tikly, M., Njobvu, P. and McGill, P. (2014) Spondyloarthritis in Sub-Saharan Africa. Current Rheumatology Reports, 16, 421. https://doi.org/10.1007/s11926-014-0421-Z

[8] Zhu, W., He, X., Cheng, K., Zhang, L., Chen, D., Wang, X., Qiu, G., Cao, X. and Weng, X. (2019) Ankylosing Spondylitis: Etiology, Pathogenesis, and Treatments. Bone Research, 7, 22. https://doi.org/10.1038/s41413-019-0057-8

[9] Tam, L.S., Gu, J. and Yu, D. (2010) Pathogenesis of Ankylosing Spondylitis. Nature Reviews Rheumatology, 6, 399-405. https://doi.org/10.1038/nrrheum.2010.79

[10] Proft, F. and Poddubnyy, D. (2018) Ankylosing Spondylitis and Axial Spondyloarthritis: Recent Insights and Impact of New Classification Criteria. Therapeutic Advances in Musculoskeletal Disease, 10, 129-139.

https://doi.org/10.1177/1759720X18773726

[11] Basakci Calik, B., Pekesen Kurtca, M., Gur Kabul, E., Telli Atalay, O., Taskin, H., Yigit, M., Tasci, M. and Cobankara, V. (2021) Investigation of the Effectiveness of Aerobic Exercise Training in Individuals with Ankylosing Spondylitis: Randomized Controlled Study. Modern Rheumatology, 31, 442-450. https://doi.org/10.1080/14397595.2020.1745409

[12] Maksymowych, W.P. (2007) Update on the Treatment of Ankylosing Spondylitis. Therapeutics and Clinical Risk Management, 3, 1125-1133.

[13] Fan, M., Liu, J., Zhao, B., Wu, X., Li, X. and Gu, J. (2020) Indirect Comparison of NSAIDs for Ankylosing Spondylitis: Network Meta-Analysis of Randomized, DoubleBlinded, Controlled Trials. Experimental and Therapeutic Medicine, 19, 3031-3041. https://doi.org/10.3892/etm.2020.8564

[14] Ibn Yacoub, Y., Amine, B., Laatiris, A., Bensabbah, R. and Hajjaj-Hassouni, N. (2012) Relationship between Diagnosis Delay and Disease Features in Moroccan 
Patients with Ankylosing Spondylitis. Rheumatology International, 32, 357-360. https://doi.org/10.1007/s00296-010-1635-7

[15] Belachew, D.A., Sandu, N., Schaller, B. and Guta, Z. (2009) Ankylosing Spondylitis in Sub-Saharan Africa. Postgraduate Medical Journal, 85, 353-357.

https://doi.org/10.1136/pgmj.2007.064717

[16] Sampaio-Barros, P.D., Costallat, L.T.L., Bertolo, M.B., Neto, J.F.M. and Samara, A.M. (2000) Methotrexate in the Treatment of Ankylosing Spondylitis. Scandinavian Journal of Rheumatology, 29, 160-162. https://doi.org/10.1080/030097400750002021

[17] Ward, M.M., Deodhar, A., Akl, E.A., Lui, A., Ermann, J., Gensler, L.S., Smith, J.A. Borenstein, D., Hiratzka, J. and Weiss, P.F. (2016) American College of Rheumatology/Spondylitis Association of America/Spondyloarthritis Research and Treatment Network 2015 Recommendations for the Treatment of Ankylosing Spondylitis and Nonradiographic Axial Spondyloarthritis. Arthritis Care \& Research, 68, 151-166. https://doi.org/10.1002/acr.22708

[18] de Avila Machado, M.A., Barbosa, M.M., Almeida, A.M., de Araújo, V.E., Kakehasi, A.M., Andrade, E.I.G., Cherchiglia, M.L. and de Assis Acurcio, F. (2013) Treatment of Ankylosing Spondylitis with TNF Blockers: A Meta-Analysis. Rheumatology International, 33, 2199-2213. https://doi.org/10.1007/s00296-013-2772-6

[19] Braun, J. and van der Heijde, D. (2003) Novel Approaches in the Treatment of Ankylosing Spondylitis and Other Spondyloarthritides. Expert Opinion on Investigational Drugs, 12, 1097-1109. https://doi.org/10.1517/13543784.12.7.1097

[20] Braun, J., Van Den Berg, R., Baraliakos, X., Boehm, H., Burgos-Vargas, R., Collantes-Estevez, E., Dagfinrud, H., Dijkmans, B., Dougados, M. and Emery, P. (2011) 2010 Update of the ASAS/EULAR Recommendations for the Management of Ankylosing Spondylitis. Annals of the Rheumatic Diseases, 70, 896-904. https://doi.org/10.1136/ard.2011.151027 